\title{
Case for diagnosis. Sclerodermiform manifestations of porphyria cutanea tarda secondary to hepatitis $C^{*}$
}

\author{
Juliana de Oliveira Alves Calado ${ }^{1}$, Luan Moura Hortencio Bastos ${ }^{1}$, Hélio Amante Miot ${ }^{1}$
}

DOI: http:/ / dx.doi.org/10.1590/abd1806-4841.20198681

\section{CASE REPORT}

A 63-year-old female patient reported blisters on the face, neck, upper, and lower limbs, which exuded and evolved as hypochromias and sclerotic areas one year ago, with no therapeutic response to topical corticosteroid therapy and phototherapy (NBUVB).
There were exulcerations and hypochromic sclerotic plaques on the face, cervical region, upper, and lower limbs, as well as areas of frontal, temporal, and occipital alopecia (Figures 1 and 2). There was restriction on wrist movement and oral opening. She did not report Raynauld's phenomenon or dysphagia, and nailfold capillaroscopy was normal.
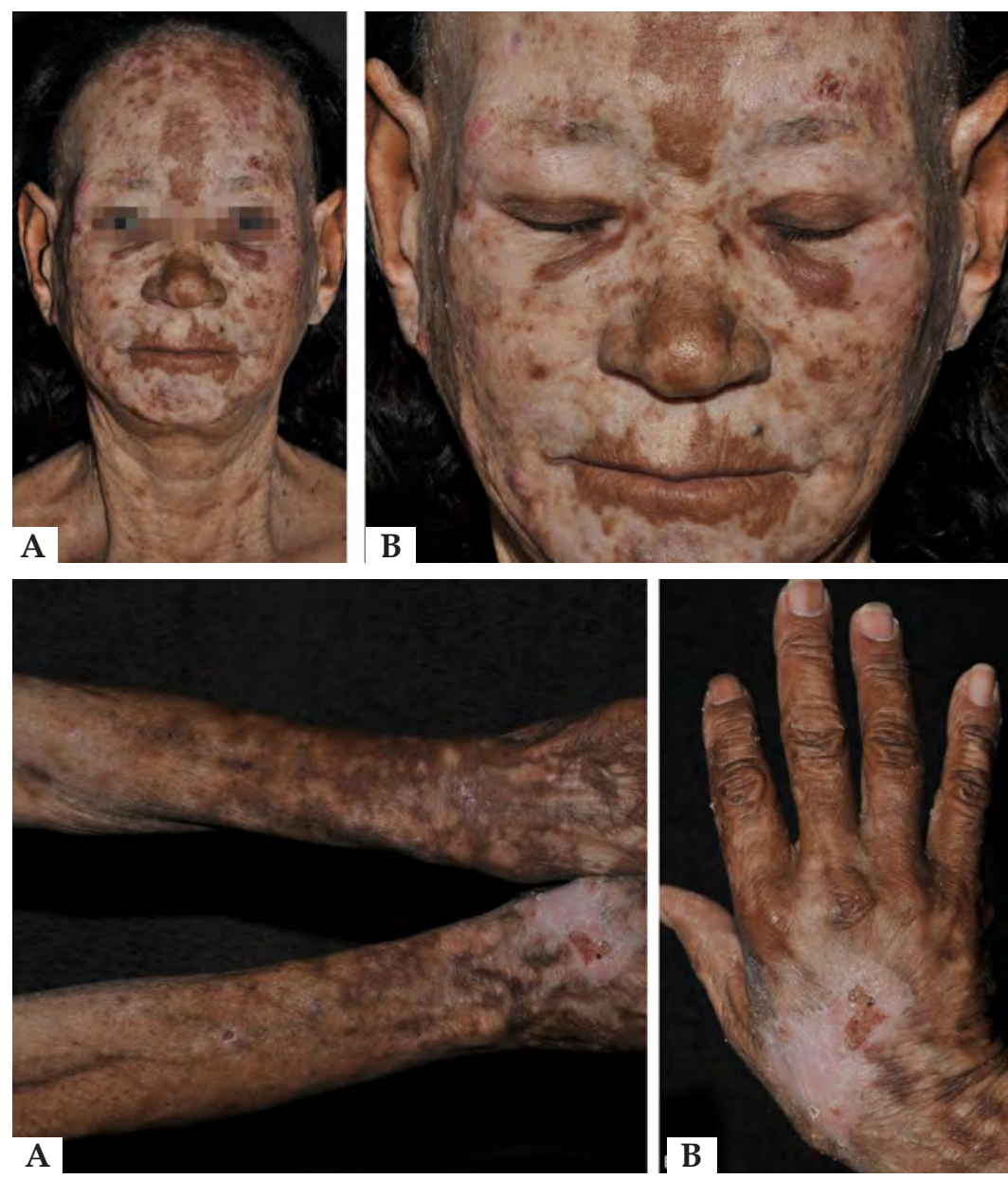

Figure 1:

A. Diffuse sclerotic hypochromic plaques on the face with alopecia. B. Detail of the dyschromic alterations, exulcerated lesion on the forehead, alopecia of the eyebrows and temporal margins

Figure 2

A. Sclerotic hypochromic plaques in the upper limbs. B. Detail of dyschromic sclerotic plaque, desquamation, and exulcerated lesion on the back of the hand

$\overline{\text { Received } 6 \text { August } 2018 .}$

Accepted 6 November 2018

* Study conducted at the Department of Dermatology and Radiotherapy, Faculdade de Medicina de Botucatu, Universidade Estadual Paulista, Botucatu, SP, Brazil.

Financial support: None.

Conflict of interest: None.

1 Department of Dermatology and Radiotherapy, Faculdade de Medicina, Universidade Estadual Paulista, Botucatu, SP, Brazil.

\section{MAILING AdDRESS:}

Hélio Amante Miot

E-mail: heliomiot@gmail.com 
There was increase in hepatic enzymes (TGO $74 \mathrm{U} / \mathrm{L}$ - reference < $36 \mathrm{U} / \mathrm{L}$, TGP $93 \mathrm{U} / \mathrm{L}$ - reference < $52 \mathrm{U} / \mathrm{L}$ ), anemia (hemoglobin $10.8 \mathrm{~g} / \mathrm{dL}$ ), and anti-HCV was positive. The other biochemical tests were normal, and anti-HIV was negative. The histopathological examination revealed upper dermis edema and thickened collagen bundles. The urinary porphyrin analysis was positive and there was reddish fluorescence in urine exposed to Wood's light (Figure 3).

\section{DISCUSSION}

In addition to the different clinical forms of cutaneous scleroderma, sclerodermiform disorders may be secondary to graft versus host disease, drugs, silica exposure, porphyrias, silicone implants, paraneoplastic manifestations, and chronic infections. ${ }^{1-7}$

The authors reported a case of porphyria cutanea tarda (PCT) - or chronic hepatic porphyria, with sclerodermiform lesions, secondary to chronic hepatitis $C$ virus, with significant involvement of photoexposed areas (face and upper limbs). ${ }^{6}$ The evolution of PCT with cutaneous sclerodermoid lesions and alopecia is uncommon, and is due to the delay in diagnosis. ${ }^{8}$

The diagnosis of PCT is given by clinical, histopathology, and porphyrin analysis. In sclerodermiform lesions, sclerosis of the

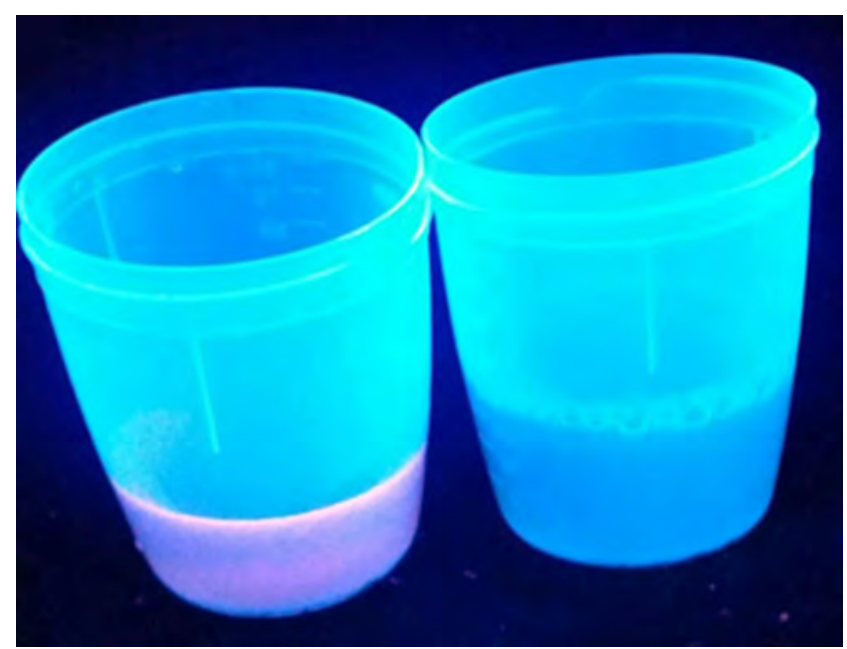

FIGURE 3: Pink-reddish fluorescence of urine exposed to Wood's light (left) compared to control urine (right) dermis is caused by an increase in collagen I, and the inflammatory infiltrate has prominent mast cells. In this case, the histopathological examination was not conclusive.

Treatment consists of identifying and suspending the triggering factor, associated with specific therapy: phlebotomy and antimalarials.

Phlebotomy promotes reduction of excess iron stocks, characteristic of porphyrias. In patients with concomitant HCV infection, phlebotomy has an additional benefit since iron reduction improves liver inflammation and response to interferon therapy. In this case, anemia contraindicated phlebotomy.

To minimize hepatotoxicity, antimalarials are used in low doses. These drugs have good results for remission of the cutaneous condition by the increase of hepatic excretion of porphyrins.

Oral antivirals for the treatment of HCV infection are the curative strategy in these situations. ${ }^{9}$ In the present case, the use of hydroxychloroquine (400mg $3 \times$ / week), photoprotection, and treatment for hepatitis $C$ with sofosbuvir and daclatasvir evolved with complete repigmentation of the lesions, reversion of alopecia, reduction of sclerosis, and normalization of porphyrins after 12 months of follow-up (Figure 4).

In six cases of sclerodermiform PCT in France, all patients were female, older than 45 years, five had alopecia and one, bullous lesions, two had hepatitis $\mathrm{C}$, and only one had hemochromatosis. ${ }^{10}$

Dermatologists should be aware of the atypical manifestations of PCT as well as the identification of hepatitis $C$ in order to indicate appropriate therapy and minimize liver morbidity. $\square$
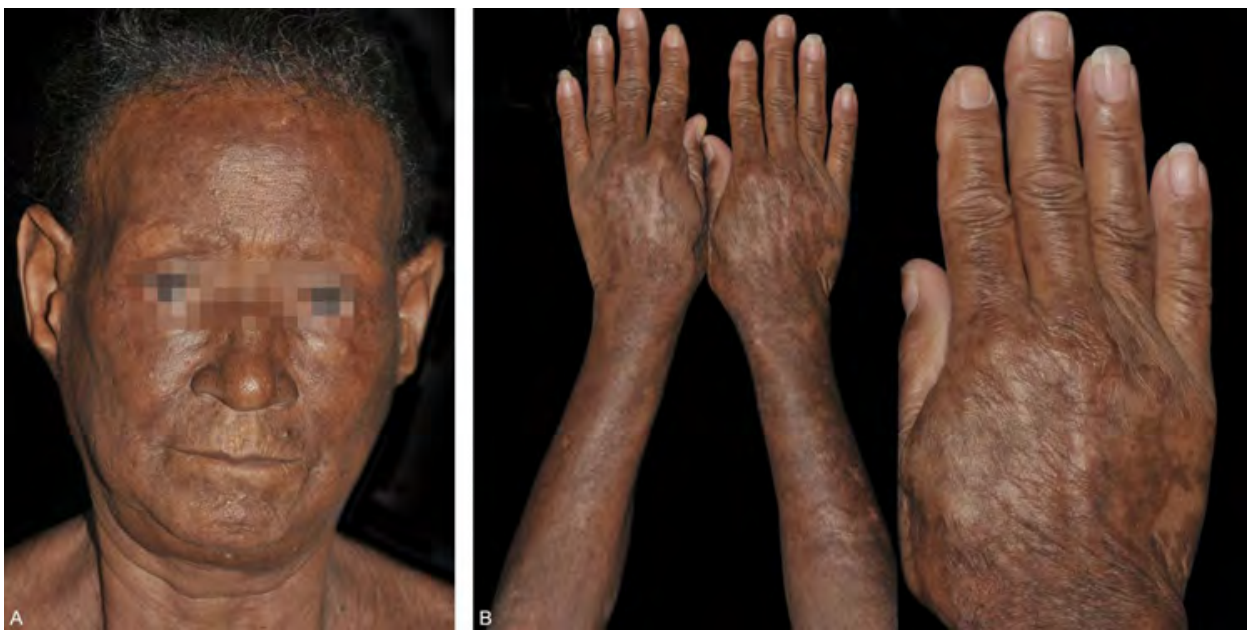

Figure 4:

Clinical picture, indicating remission after treatment with hydroxychloroquine, photoprotection, and cure of hepatitis C 
Abstract: A 63-year-old black female patient with blisters and exulcerations on the face, neck, upper limbs, and subsequent evolution with hypochromic sclerotic areas and alopecia, is reported. Chronic hepatitis C and presence of high levels of porphyrins in urine were demonstrated. There was complete remission with the use of hydroxychloroquine, photoprotection, and treatment of hepatitis. Significant sclerodermoid involvement of the skin as a manifestation of porphyria cutanea tarda secondary to hepatitis $C$ emphasizes the importance of diagnostic suspicion regarding skin manifestation in order to indicate the appropriate therapy, and to minimize the hepatic morbidity.

Keywords: Scleroderma, localized;Hepatitis C; Porphyria cutanea tarda; Porphyrias; Porphyrias, hepatic

\section{REFERENCES}

1. Haustein UF, Haupt B. Drug-induced scleroderma and sclerodermiform conditions. Clin Dermatol. 1998;16:353-66.

2. Rovisco J, Serra S, Abreu P, Coutinho M, Santiago T, Inês L, et al. Paraneoplastic sclerodermiform syndrome--case report. Acta Reumatol Port. 2014;39:87-90.

3. Anandan S, Othman M, Cheong I, Chin GL. Scleroderma secondary to silica exposure--a case report. Singapore Med J. 1995;36:559-61.

4. Aounallah A, Lahouel I, Mokni S, Ksiaa M, Hayouni M, Belajouza C, et al. Atypical generalized morphea-like scleroderma occurring in a patient exposed to organic solvents and having chronic hepatitis $\mathrm{C}$ virus infection. Indian J Dermatol Venereol Leprol. 2018;84:221-4.

5. Wackernagel A, Bergmann AR, Aberer E. Acute exacerbation of systemic scleroderma in Borrelia burgdorferi infection. J Eur Acad
Dermatol Venereol. 2005;19:93-6.

6. Tsukazaki N, Watanabe M, Irifune H. Porphyria cutanea tarda and hepatitis C virus infection. Br J Dermatol. 1998;138:1015-7.

7. Franzon VA, Mikilita ES, Camelo FH, Camargo R. Porphyria cutanea tarda in a HIV-positive patient. An Bras Dermatol. 2016;91:520-3.

8. Zemtsov R, Zemtsov A. Porphyria cutanea tarda presenting as scleroderma. Cutis. 2010;85:203-5.

9. Tong Y, Song YK, Tyring S. Resolution of Porphyria Cutanea Tarda in Patients With Hepatitis C Following Ledipasvir-Sofosbuvir Combination Therapy. JAMA Dermatol. 2016;152:1393-5.

10. Khayat R, Dupuy A, Pansé I, Bagot M, Cordoliani F. Sclerodermatous changes in porphyria cutanea tarda: six cases. Ann Dermatol Venereol. 2013;140:589-97.

\footnotetext{
Juliana de Oliveira Alves Calado $\quad$ (D) ORCID 0000-0002-3740-3458

Approval of the final version of the manuscript; elaboration and writing of the manuscript; obtaining, analyzing and interpreting the data; intellectual participation in propaedeutic and/or therapeutic conduct of the cases studied; critical review of the literature; critical review of the manuscript.

Luan Moura Hortencio Bastos $\quad$ (D) ORCID 0000-0003-3636-2161

Approval of the final version of the manuscript; elaboration and writing of the manuscript; obtaining, analyzing and interpreting the data; intellectual participation in propaedeutic and/or therapeutic conduct of the cases studied; critical review of the literature; critical review of the manuscript.

Hélio Amante Miot $\quad$ (D) ORCID 0000-0002-2596-9294

Approval of the final version of the manuscript; conception and planning of the study; elaboration and writing of the manuscript; obtaining, analyzing and interpreting the data effective participation in research orientation; intellectual participation in propaedeutic and/or therapeutic conduct of the cases studied; critical review of the literature; critical review of the manuscript.
}

How to cite this article: Calado JOA, Bastos LMH, Miot HA. Case for diagnosis. Sclerodermiform manifestations of porphyria cutanea tarda secondary to hepatitis C. An Bras Dermatol. 2019;94(4):479-81. 